Proc. Indian Acad. Sci. (Earth Planet. Sci.), Vol. 94, No. 1, March 1985, pp. 35-41.

(C) Printed in India.

\title{
Vertical component MAGSAT anomalies and Indian tectonic boundaries
}

\author{
J G NEGI, P K AGRAWAL and N K THAKUR \\ National Geophysical Research Institute, Hyderabad 500007, India
}

MS received 18 February 1984; revised 15 October 1984

\begin{abstract}
MAGSAT vertical component (Z-component) of crustal anomalies are correlated for the first time with major geological and tectonic boundaries/features of the Indian subcontinent. A prominent 'low' is consistently observed on all the profiles centred between $19^{\circ}$ and $23^{\circ}$ latitudes over the broad Peninsular 'high'. The other conspicuous 'low' indicated from the present work is confined to the region above Sarda depression $\left(29^{\circ} \mathrm{N}\right.$ to $\left.31^{\circ} \mathrm{N}\right)$ in the foothills of Himalayas. Interesting magnetic signatures are identified over the Narmada-Son rift and Godavari graben.
\end{abstract}

Keywords. MAGSAT anomalies; tectonic boundaries; correlation studies.

\section{Motivation}

The investigations through POGo satellite data revealed the presence of prominent crustal magnetic anomalies even at the satellite heights. The distribution of the crustal magnetic anomalies at satellite level is expected to be controlled by the juxtaposition of the large size geological and tectonic features in addition to magnetic and thermal properties of different deep-rooted structures. The presence of anomalous signatures at satellite heights would necessitate a novel approach for the estimation of parameters of the deep-seated causative sources. These global and regional anomalies of long spatial wavelengths have been correlated to subsurface lithological features by Regan et al (1975) and Langel et al (1980).

More precise and accurate data of MAGSAT have confirmed the results of POGO and in few areas resolved new shorter wavelength anomalies (Langel et al 1982; Frey 1982). However, Sailor et al (1982) concluded from the spectral characteristics of the MAGSAT data that anomalies of wavelength of the order of $700 \mathrm{~km}$ can be resolved well, and around $250 \mathrm{~km}$ wavelength with some uncertainty.

The present mapping of world-wide POGO and MAGSAT data has identified a magnetic 'low' over Himalayas and 'high' over the Peninsular India. The Indian subcontinent is comprised of several tectonic provinces of different nature and origin, and it is in this view interesting to (i) study the finer structure of these anomalies, and (ii) define constraints for understanding of the deep-rooted causes of these features.

\section{Data selection and profile description}

It has been customary to prepare the total intensity map from the satellite data. However, presentation of such data is likely to pose the following problems for the Indian region: 
(i) The amplitude of observed total field anomalies are generally too small to be significant for correlating mainly with crustal features of short wavelengths $(\approx 300 \mathrm{~km}$ ). On the other hand, MAGSAT vertical intensity data seems to resolve the anomalies better as is evident from the figure 1.

(ii) The intercomparison of the magnetic anomalies due to crustal sources distributed over different regions bring in complications due to: (a) assumption of induced magnetisation, (b) induction processes at high and low geomagnetic latitudes, and (c) their distribution over different geomagnetic latitudinal zones.

For better comparison, it is thus natural to reduce the total intensity data to pole. However, such transformation from the low latitude data may not be worthwhile owing to the dominance of the horizontal component of the field, and

(iii) The transient geomagnetic variations for night hours are mainly due to magnetospheric currents, whose configuration is such that they produce uniform but significant horizontal field variations and almost negligible vertical transient field variations at the surface of the earth at low geomagnetic latitudes (Schmucker 1970).

Under the above considerations we have preferred to present the vertical component profiles over the Indian region (figure 2). The latitudinal extent of all the selected

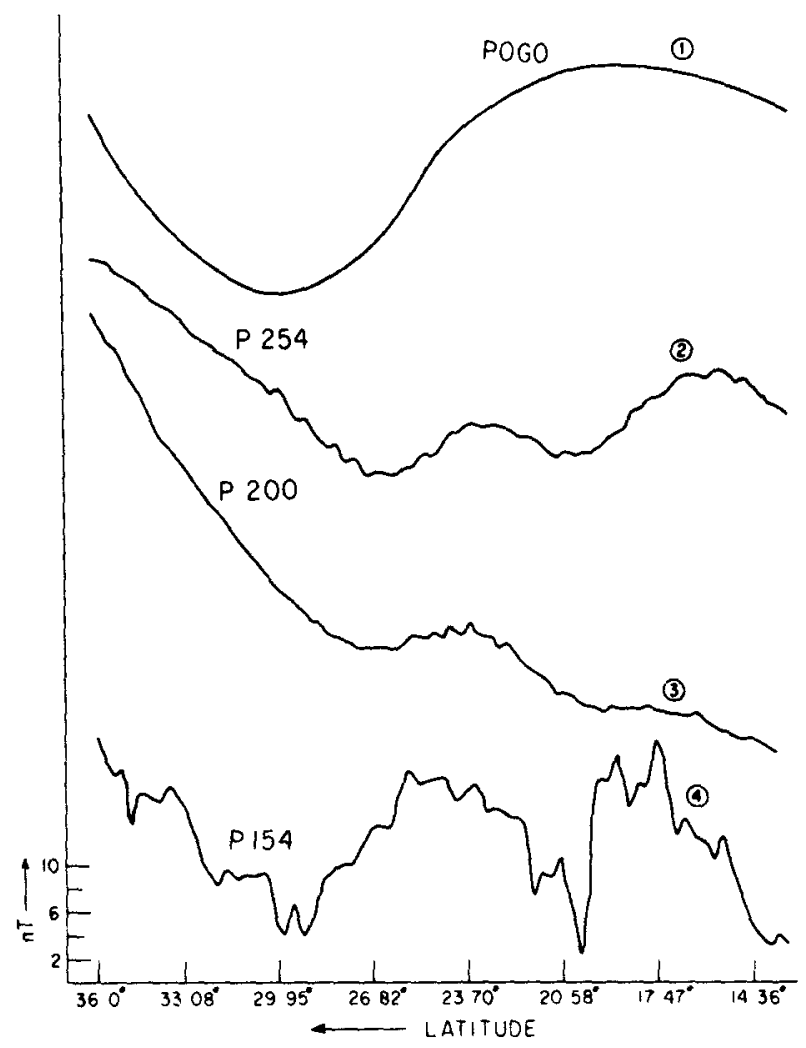

Figure 1. Magnetic responses at satellite level: 1. POGo-Total intensity (scalar) 2 and 3 . MAGSAT-Total intensity (scalar) 4. MAGSAT-vertical intensity. 


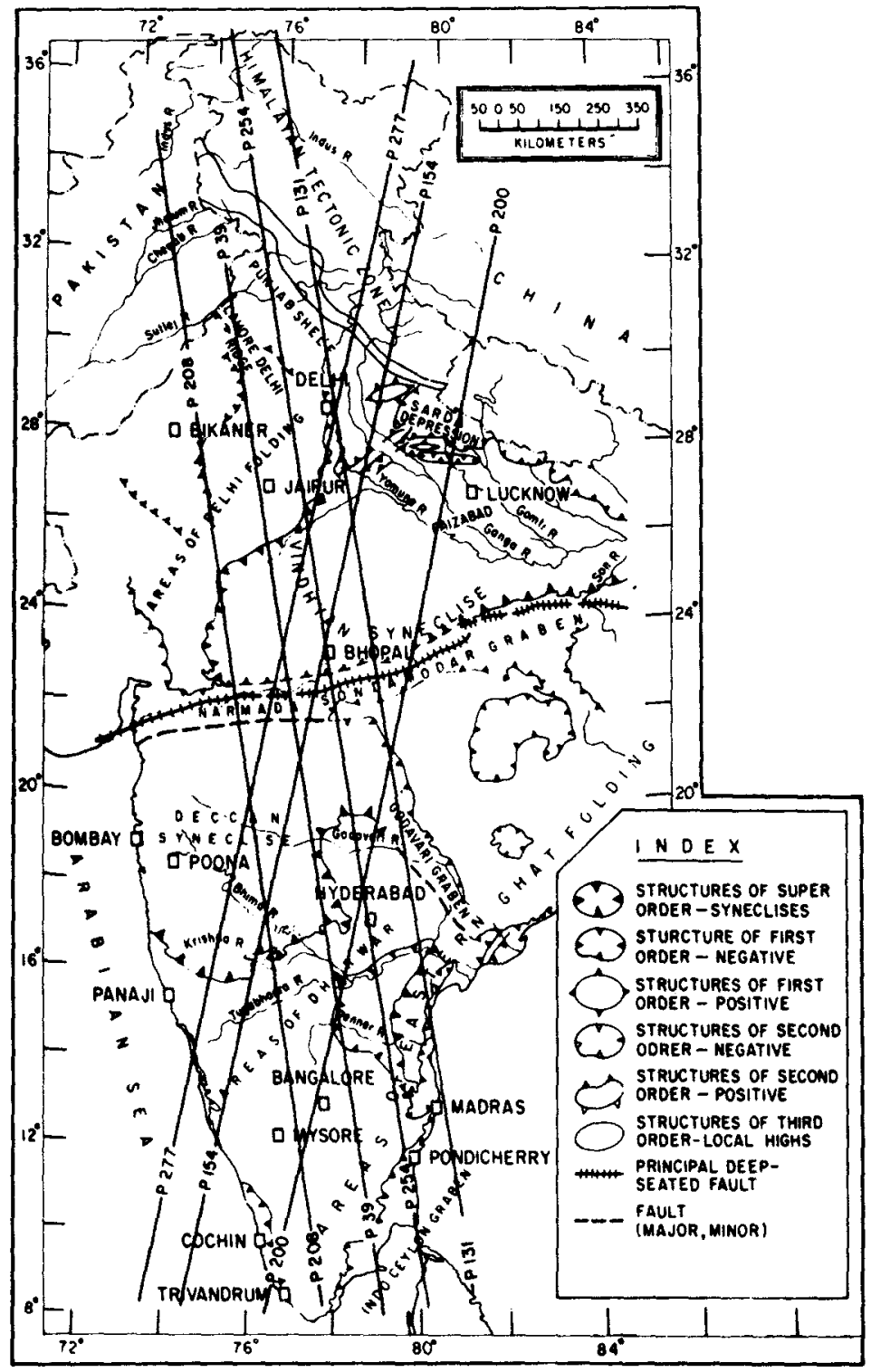

Figure 2. MAGSAT passes over major geological and tectonic features of the Indian subcontinent.

profiles is from $36^{\circ} \mathrm{N}$ to $9^{\circ} \mathrm{N}$ with different longitudinal trajectories. The profiles cut across the major geological and tectonic boundaries of India. The data obtained from MAGSAT investigator-B tapes was sampled at $36 \mathrm{~km}$ spacing. The range of altitude for selected profiles was from $388 \mathrm{~km}$ to $466 \mathrm{~km}$ (table 1), and no sharp altitude jumps were noted for the analysed data. The residual vertical field was obtained by subtracting the model (MGsT 4/81) vertical field values from the observed values. The residuals thus obtained will contain the effects of (a) time-varying external fields due to the currents in 
Table 1. Altitude range of the spacecraft for the selected MAGSAT Passes

\begin{tabular}{|c|c|c|c|c|c|c|c|c|}
\hline \multicolumn{2}{|l|}{ Pass No. } & \multirow{2}{*}{$\frac{254}{368}$} & \multirow{2}{*}{$\frac{131}{406}$} & \multirow{2}{*}{$\frac{208}{379}$} & \multirow{2}{*}{$\frac{39}{444}$} & \multirow{2}{*}{$\frac{200}{411}$} & \multirow{2}{*}{$\frac{277}{439}$} & \multirow{2}{*}{$\frac{154}{397}$} \\
\hline Altitude & $\operatorname{Max}$ & & & & & & & \\
\hline range $(\mathbf{k m})$ & Min & 398 & 448 & 412 & 489 & 450 & 482 & 437 \\
\hline \multicolumn{2}{|c|}{$\begin{array}{l}\text { Mean altitude } \\
(\mathbf{k m})\end{array}$} & 388 & 427 & 395 & 466 & 433 & 460 & 417 \\
\hline
\end{tabular}

the ionosphere and magnetosphere, and (b) fields due to crustal origin. The former can be minimised by selecting data for magnetically quiet period. In the present case, the selected profiles are generally for night hours and the $K_{p}$ index ranges from 0 to 20 . The geomagnetic variations as observed at Hyderabad Observatory for the chosen profiles produce insignificant time-varying fields.

Under the above considerations, we are left with data which might be expected to contain magnetic response from the subsurface features. However, such data is superimposed on different noises which are (a) long wavelength fields (due to magnetospheric ring currents), (b) instrumental noise (high frequency oscillations of the order of $1 \mathrm{nT}$; Mayhew et al 1980), and (c) fields due to local external currents.

Due to the presence of these, extraction of meaningful signatures and their interpretation in terms of causative sources really becomes difficult. It may, however, be mentioned here that the present investigations are mainly confined to detect the magnetic responses which are superimposed over broad linear trends. Correction for these trends are not applied as it may not necessarily very much improve the response we are looking for. One way of overcoming the problem due to other noise levels is to look for consistent pattern of magnetic signatures over the known geological and tectonic features in different satellite passes. The repeatability of responses in various passes coincident with geological and tectonic boundaries indicates that the response from a particular geological configuration is indeed real.

\section{Correlation studies}

The crustal anomalies at satellite level are expected to be controlled by (i) lateral variations in the physical, chemical and thermal properties of various subsurface rock formations forming different types of tectonic and geological boundaries, and (ii) the variations in thickness of the uniformly magnetised crustal layers. The assemblage of these factors produce magnetic signatures of different shapes and amplitudes at the observing site. In view of this, an attempt to investigate meaningful signatures of the complex geological and tectonic boundaries of the Indian subcontinent through the MAGSAT data may be illuminating.

\section{Long wavelength anomalies}

In most of the profiles (figure 3) we confirm the broad 'low' over Himalayas and 'high' over Peninsular India as obtained by Regan et al (1975), Langel et al (1982) and Frey 


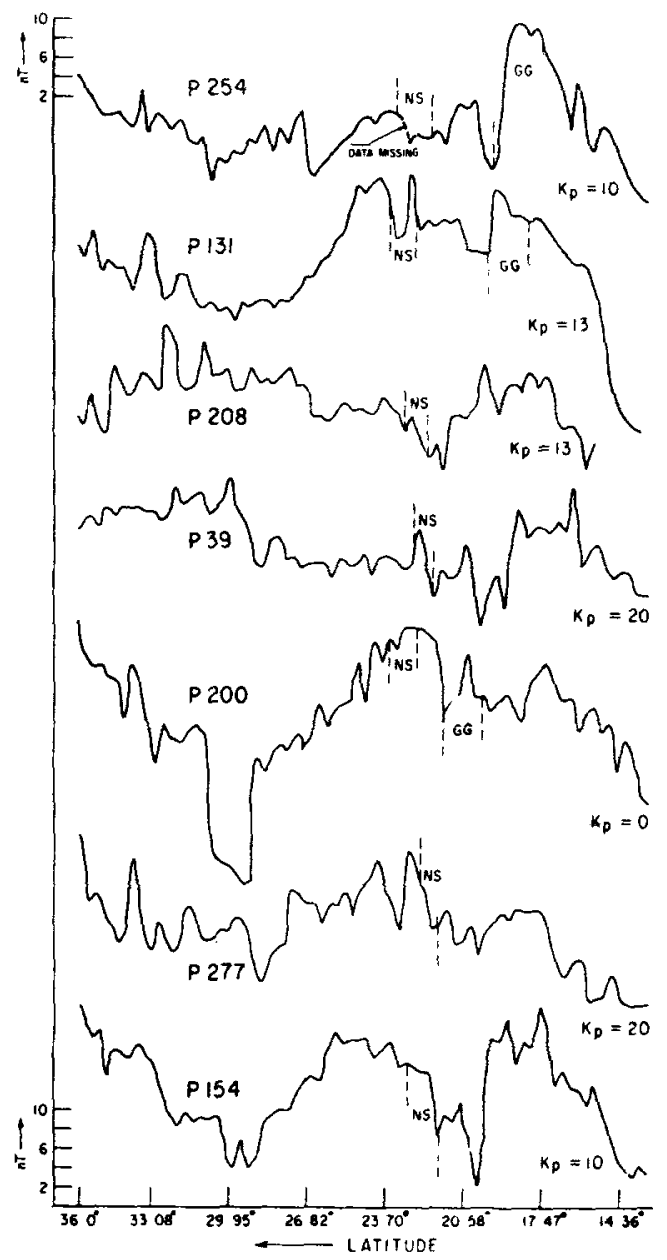

Figure 3. MAGSAT vertical intensity response along different passes. NS and GG represent respectively the Narmada-Son lineament and Godavari graben.

(1982) from total intensity data. The additional striking feature brought out here on most of the profiles is a 'low' centred between $19^{\circ}$ and $23^{\circ}$ latitudes over the broad Peninsular 'high'. Interestingly, the present area encompasses the major rift zones of Peninsular India which is also evident from the gravity anomaly pattern of the region. The features could be attributed either to lateral changes in magnetic intensity of the subsurface geological formations or to changes in thickness of uniformly magnetised subsurface layers or both. The deep seismic sounding results of Kaila et al (1981) suggest downwarping of the crust in this area. The nature of long wavelength anomalies over Peninsular India indicates that the sources are deep-rooted possibly extending down to lithosphere.

The other prominent 'low' as indicated by the present work is confined to the region N-E of Ganga basin and above the Sarda depression under the foothills of Himalayas $\left(29^{\circ} \mathrm{N}\right.$ to $\left.31^{\circ} \mathrm{N}\right)$. The gravity map of India (Qureshy 1970) shows sharp gradient over 
this region. Geomagnetic depth sounding results (Arora et al 1982) indicated a prominent conductive structure which coincides with the seismically active DelhiHaridwar ridge (Kaila and Narain 1976). The presence of magnetic signatures in most of the passes over this region is indicative of deep-rooted structure in the foot-hills of Himalayas. The correlation of the above mentioned geophysical results assumes importance in understanding the proper geodynamical significance of the area. Superimposed on these are relatively smaller wavelength anomalies which are described here.

\subsection{Narmada-Son structure}

The Narmada-Son lineament traverses west to east and almost bisects the Indian subcontinent. This is a tectonic feature of Precambrian origin and is characterised by two faults viz Narmada-Son and Tapti faults. The faults give rise to rift valleys delimiting the Satpura horst. The faults are reported to be reaching quite deep extending even upto upper mantle (Ray 1967).

The magnetic signatures in most of the profiles over Narmada-Son are characterised by an initial rise and then a sharp fall (North-south direction) indicative of a fault-like structure. The presence of this signature at satellite height confirms the deep-rooted cause of the structure as suggested by Ray (1967).

\subsection{Godavari graben anomaly?}

Godavari graben also had its origin in Precambrian times and possibly connected to eastern ghat orogeny. Cratonic and sedimentary basin studies by Naqvi et al (1974) and Sastri et al (1981) indicate respectively that the graben extends $800 \mathrm{~km}$ in length and its width varies from 50 to $100 \mathrm{~km}$ or even more. The Godavari graben extends upto Narmada-Son lineament which probably indicates that the structure is wider near the vicinity of the rift junction (figure 2). The present MAGSAT passes cut across the graben where the width is substantially large.

Over the Godavari graben (between $20^{\circ}$ and $22^{\circ}$ latitudes) a rise in amplitude is observed. It is quite intriguing, however, to observe such an anomaly in different passes (P 131, 200, 254) at the satellite level. Similar nature of anomaly in all the three profiles suggests that the response from the structure is real. This magnetic signature might possibly indicate differences in broad subsurface configuration at deeper level and needs detailed study with finer grid data in the light of existing geophysical information.

\section{Conclusions}

In the present work the hitherto untried vertical component MAGSAT profile data brings out magnetic anomalies which coincide with the major geological and tectonic boundaries of the Indian subcontinent. A new finding from the present data is a conspicuous magnetic 'low' over the broad Peninsular 'high' suggesting a deep basinlike structure. Besides, magnetic 'low' above the Ganga basin, a 'low' over NarmadaSon rift and a 'high' over the northern part of Godavari graben are the significant signatures recorded at the satellite level indicative of their deep-rooted sources. 
The anomalous response of Godavari graben is quite intriguing and needs further detailed study. The quantitative interpretation of satellite data needs to be done with great caution in view of the varying altitudes and geomagnetic inclinations.

\section{Acknowledgements}

The investigation has been carried out, with the aid of MAGSAT data made available by NASA, to Survey of India. The authors are grateful to NASA, Surveyor General and Col. (Dr.) Arur of Survey of India, Dehradun for providing us the copy of the tapes of the Magsat data. Thanks are also due to Dr M N Qureshy of the Department of Science and Technology, New Delhi (India) for coordinating various aspects of MAGSAT research programmes in India. The authors are also thankful to Messrs P. V. Swamy, N. K. Ganesh, J. P. Sastry and Shyam Vaidya for assistance.

\section{References}

Arora B R, Lilley F E M, Slone M N, Singh B P, Srivastava B J, and Prasad S N 1982 Geophys. J.R. Astr. Soc. 69459

Frey H 1982 Geophys. Res. Lett. 9299

Kaila K L, Murthy P R K, Rao V K and Kharetchko G E 1981 Tectonophysics 73365

Kaila K L and Narain H 1976 Proc. Himalayan Geol. Sem. Section 2 pp. 1-30

Langel R A, Coles R and Mayhew M A 1980 Can. J. Earth Sci. 17876

Langel R A, Phillips J D and Horner R J 1982 Geophys. Res. Lett. 9269

Mayhew M A, Johnson B D and Langel R A 1980 Earth Planet. Sci. Lett. 51189

Naqvi S M, Rao V D and Narain H 1974 Precambrian Res. 1345

Qureshy M N 1970 Proc. II Symp. Upper Mant. Proj. Hyd. 1-24

Ray S 1967 Sci. Cult. 33252

Regan R D, Cain J C and Davis W M 1975 J. Geophys. Res. 80794

Sailor R V, Lazarowics A R and Bramer R F 1982 Geophys. Res. Lett. 9289

Sastri V V, Venkatachala B S and Narain V 1981 Int. Symp on continental margin (Amsterdam: Elsevier)

Schmucker U 1970 Bull. Scripps. Inst. Oceanogr. 131 